\title{
Fight Against COVID-19: ARCl's Technologies for Disinfection
}

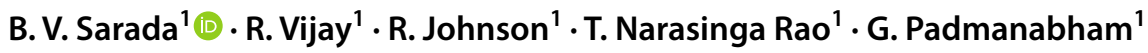

Received: 4 June 2020 / Revised: 23 June 2020 / Accepted: 6 July 2020 / Published online: 14 July 2020

(C) Indian National Academy of Engineering 2020

\begin{abstract}
COVID-19 (SARS-CoV-2) is causing a huge concern to the global population due to its highly contagious properties. The SARS-CoV-2 is a new variant in the coronavirus family. The world is focussing on several methods to battle against this novel corona virus, including control of its spread. In this context, ARCI has quickly made efforts to develop disinfection systems including a UVC-based disinfection trolley, honeycomb air heater and a fogging chamber using UVC germicidal lamps, dry heat sterilization and HOCl-based chemical disinfectant to provide rapid and effective inactivation of microorganisms causing the pandemic. These systems have been successfully deployed at different hospitals for their validation.
\end{abstract}

Keywords SARS-CoV-2 $\cdot$ Disinfection systems $\cdot$ UVC radiation $\cdot$ Heat sterilization $\cdot$ HOCL

\section{Introduction}

The recent outbreak of the novel coronavirus, known as COVID-19, has caused a pandemic, which is a worldwide concern and World Health Organization (WHO) has declared a global health emergency. The experts from the International Committee on Taxonomy of Viruses (ICTV) named it as SARS-CoV-2 virus as the receptor-binding gene region has a structure which is similar to that of SARS coronavirus. It has been shown by several research groups that the virus uses the same entry receptor, known as angiotensin-converting enzyme 2 (ACE2) (Hofmann and Pohlmann 2004; Zhou et al. 2020). The acute respiratory disease which is caused by the present coronavirus is observed to be through transmission via respiratory droplets, direct contact with the infected person and also through contaminated surfaces. No vaccine or direct medicine is available for treating the persons infected by this virus and it is expected to take several months for bringing out either a vaccine or medicines for the treatment. Therefore, it is very important to prevent the spread of the virus both in health-care premises and public places. SARS-CoV-2 is shown to be more stable on plastic

\footnotetext{
B. V. Sarada

sarada@arci.res.in

1 International Advanced Research Centre for Powder Metallurgy and New Materials (ARCI), Balapur (PO), Hyderabad, Telangana 500005, India
}

as well as stainless steel surfaces when compared to copper surfaces (Doremalen 2020).

Although studies on the transmission of the coronavirus from the surfaces that are contaminated to human hands are not yet available, from the data available, it is noted in case of the influenza virus that a $5 \mathrm{~s}$ of contact time can transfer about $31 \%$ of the virus (Kampf et al. 2020). In fact, a report presented on studies performed on students has shown that touching the face with hands on an average is $\sim 23$ times $/ \mathrm{h}$, which may cause a transmission of the virus (2015). Therefore, during a situation of pandemic, it is necessary to minimize the viral load on frequently touched surfaces, especially in the vicinity of patient care rooms as primary importance, where the highest viral load is expected. In addition, with the official and public activities slowly resuming, there is an utmost necessity for quick disinfection methods at the various work places, public transport system and commercial outlets.

Though the virus survives as aerosols and on environmental surfaces for various durations of time, it can easily be inactivated by several types of physical and chemical disinfection methods (Mackenzie 2020) including UVC disinfection (Malayeri et al. 2020), dry-heat sterilization (Rutala and Weber 2019) and using biocidal agents (Lei Liao 2020). The Centre for Disease Control and Prevention (CDC) has also recommended these disinfection methods for bacteria and viruses involving protein denaturation and DNA/RNA disruption (Guideline for disinfection and sterilization in healthcare facilities 2008). Although entire UV radiation is 
available from Sun, the radiation with UVC is completely absorbed by the Earth's atmosphere and therefore UVC radiation can be made available only through UVC lamps. The second method uses dry heat with advantages such as nontoxicity and environmental friendliness. Similarly, several biocidal agents such as hydrogen peroxide, $\mathrm{HOCl}$ and $\mathrm{NaOCl}$ are used as disinfectants worldwide, especially for fogging, with prime importance in health-care facilities (Abreu et al. 2013; Djimeli et al. 2014).

ARCI has made efforts and successfully developed disinfection systems for combating COVID-19 effectively at medical as well as public settings. Physical, dry heat and chemical disinfection methods have been developed by using UVC lamps, honeycomb air heater and $\mathrm{HOCl}$ fogging system, respectively.

\section{ARCl's Disinfection Systems}

\section{UV Disinfection Trolley}

ARCI, in collaboration with University of Hyderabad (UoH) and Mekins Industries Ltd. (MIL), has co-developed a UVC disinfection trolley to fight against COVID-19 by a simple physical process where rapid cleaning is possible within few minutes especially in hospital settings avoiding the use of harsh chemicals. Although the entire UV spectrum can kill or inactivate several microorganisms, UVC energy at $253.7 \mathrm{~nm}$ is the most effective for germicidal action (Fig. 1).

SARS-CoV-2 virus is enveloped by a fragile outer lipid envelope, similar to other coronaviruses, making it more susceptible to disinfectants compared to non-enveloped viruses such as rotavirus, norovirus and poliovirus (Guideline for Disinfection and Sterilization in Healthcare Facilities (2008)). In addition, SARS-CoV-2 sustains for a very long time on surfaces, causing rapid spread (Abreu et al. 2013; Djimeli et al. 2014). UVC radiation is very well known to

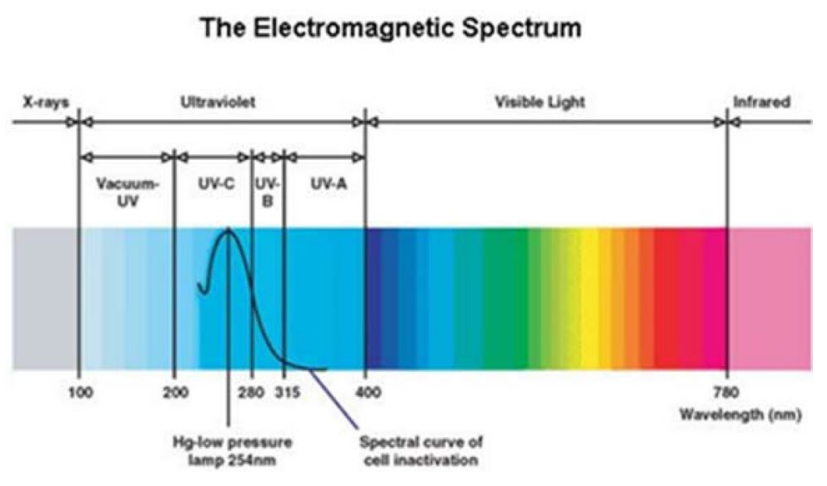

Fig. 1 Electromagnetic spectrum highlighting UVC radiation (reproduced from https://www.alfaauv.com/blog/uv-and-disinfection-ofwater/) inactivate most of the microorganisms, including viruses, bacteria, fungus, algae etc., by forming pyrimidine dimers. The dimerization process disturbs the replication of RNA or DNA, leading to cell destruction (Darnella et al. 2004). SARS-CoV-2 belongs to the large family of COVs with single-stranded RNA viruses (ssRNA). Although the dynamics of SARS-CoV-2 are still unknown, ssRNA is known to be more sensitive to UVC than double-stranded DNA ( $d s$ DNA) (Tseng and $\mathrm{Li}$ 2007). According to the International Ultraviolet Association (IUVA), UV disinfection technologies can play a major role in reducing the transmission of the virus causing COVID-19 based on existing disinfection data and empirical evidence reported for other viruses (McDevitt et al. 2012). UVC (200-280 nm) has been extensively studied for its ability to disinfect air, water and surfaces and thus can reduce the risk of acquiring infection, when used with proper care.

Environmental surfaces in hospitals include furniture such as tables, chairs, walls, and other stationary items inside the patient-care rooms and washrooms in addition to surfaces of non-critical medical equipment. Used patient beds and the rooms can be decontaminated rapidly before the admission of the next set of patients which is a major requirement in several hospitals due to the limited availability of beds and increasing number of patients, in a pandemic situation.

The UVC disinfection trolley developed by ARCI, UoH, and MIL consists of six UVC germicidal tubes ( $30 \mathrm{~W}$ each), which are arranged in such a way that either three sides are illuminated with two tubes facing each direction or the tubes are arranged in a semicircular manner (https://dst.gov.in/uvdisinfection-trolley-can-effectively-clean-hospital-space s-combat-covid-19). While these lamps take care of disinfection on the walls, bed, and room air, the floor disinfection is done by two smaller UV lights ( $15 \mathrm{~W}$ each) located at the bottom facing the floor. The hospital rooms get disinfected when the trolley is moved around in the room by an operator in protective suit and UV-resistant goggles.

The irradiance measurements were performed for the UVC lamps at different distances. Based on these irradiance measurements, from the calculations done, the UVC trolley can be operated with an average speed of $5 \mathrm{ft} / \mathrm{min}$ to cover a room of 400 sq.ft. and a disinfection of $>99 \%$ can be achieved within $30 \mathrm{~min}$. The present system is the first prototype and is readily usable in hospitals, railway coaches that are also being planned for treatment of COVID-19 patients and commercial outlets. Systems with smaller dimensions and further automation are in progress in view of rapid disinfection required at public transport systems. The present system has been deployed at the Employee's State Insurance Corporation (ESIC) hospital in Hyderabad and tests have been done for the bacterial disinfection by exposing different types of bacteria to the UVC lamps. It has been shown 
from the studies performed that the system has the capability of disinfecting the microbial organisms completely within 2 min of irradiance (Fig. 2).

However, care should be taken to operate the UVC-light disinfection system in unoccupied rooms, after the patient is discharged and in the absence of healthcare personnel, since the UVC light can be absorbed by organic molecules and may cause damage to the skin and retina.

\section{Honeycomb Air Heater-Based System}

According to recent studies (Rutala and Weber 2019; Heating the best method for disinfection of N95 masks, finds study 2020), heating is viewed as the best and efficient method for COVID-19 virus disinfection of PPEs including N95 masks. Heat-based disinfection process is advantageous, as it does not employ any volatile organics or radiations and is expected to be effective for disinfection as the heat penetrates throughout the bulk of the PPEs. A unique and innovative energy-efficient disinfecting device has been jointly developed and a patent filed (Johnson et al. 2020) by ARCI and M/s. Sowbal Aerothermics, Hyderabad, for the quick disinfection of microbe/virus-infected PPEs for reuse. The device is based on honeycomb-based air heater technology which produces dry/moist heat over a wide range of temperature and relative humidity. The device is portable, lightweight and compact, along with an instant generation of heat for quick disinfection process. A high temperature post heater is also installed in the exhaust line to ensure the disinfection of air from the chamber before letting the air to the atmosphere. The first prototype is shown schematically in Fig. 3 and the device is ready for testing and evaluation for its disinfection capabilities (Fig. 3).

\section{HOCl-Based Fogging Tower}

The other system developed by ARCI is an HOCl-based fogging unit which is a chemical disinfectant and antimicrobial and virucidal agent. This is to disinfect the places where there is a large amount of public movement and the danger of the pandemic spreading rapidly exists.

Hospitals, health-care facilities, public places, food manufacturing units, sanitary services, etc., regularly use chemical disinfectants for eradication of microbial organism. However, the material safety data for several of the virucidal chemicals do not allow their use through spraying or fogging, owing to their toxicity and their adverse effect on humans, causing ill-health depending on the duration of exposure and concentration of the sprays (https ://www.epa.gov/pesticide-registration/selected-epa-regis tered-disinfectants). Among theses, sodium hypochlorite and hypochlorous acid are the most popular disinfectants
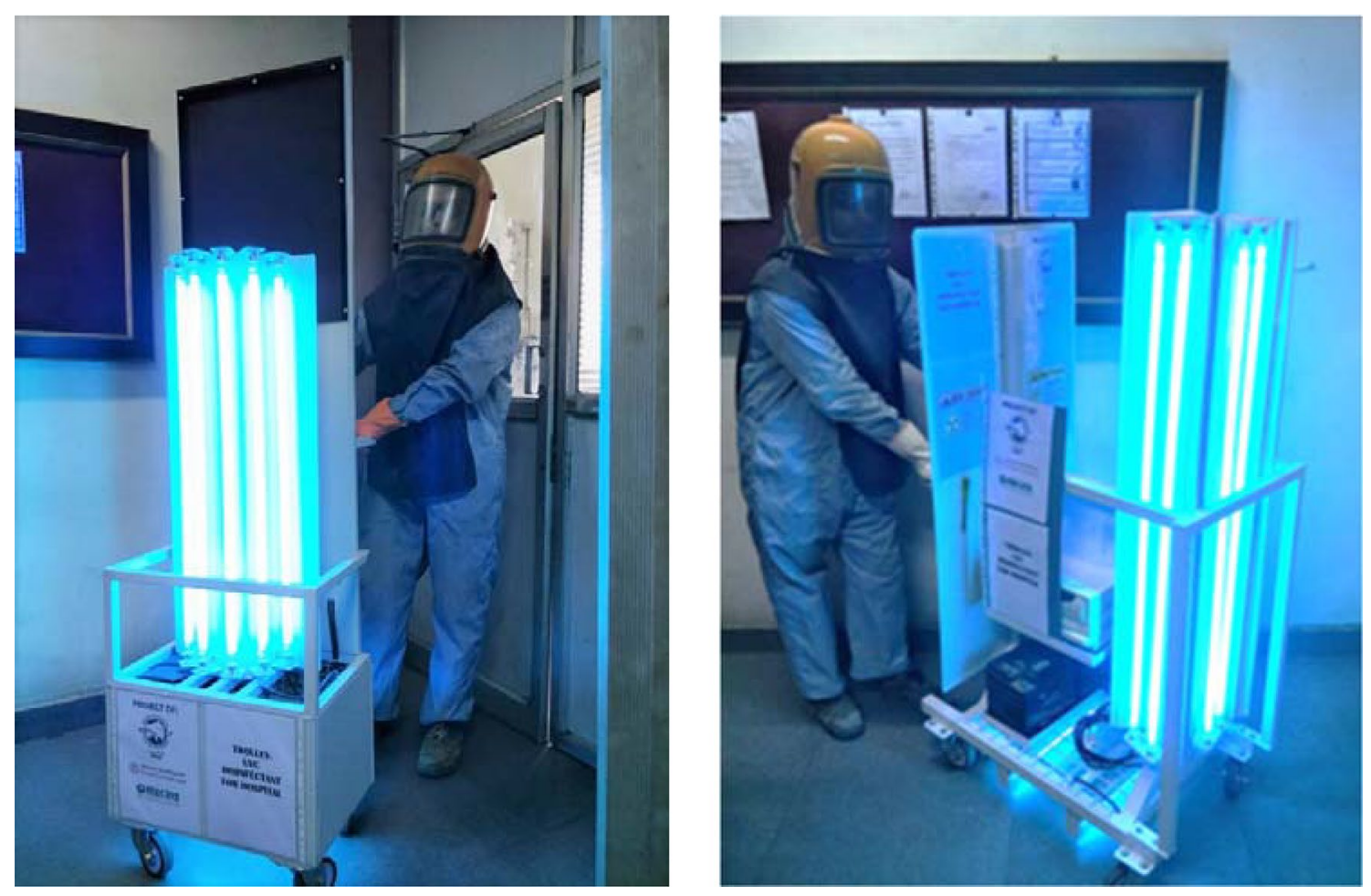

Fig. 2 UV disinfection trolley models developed by ARCI 


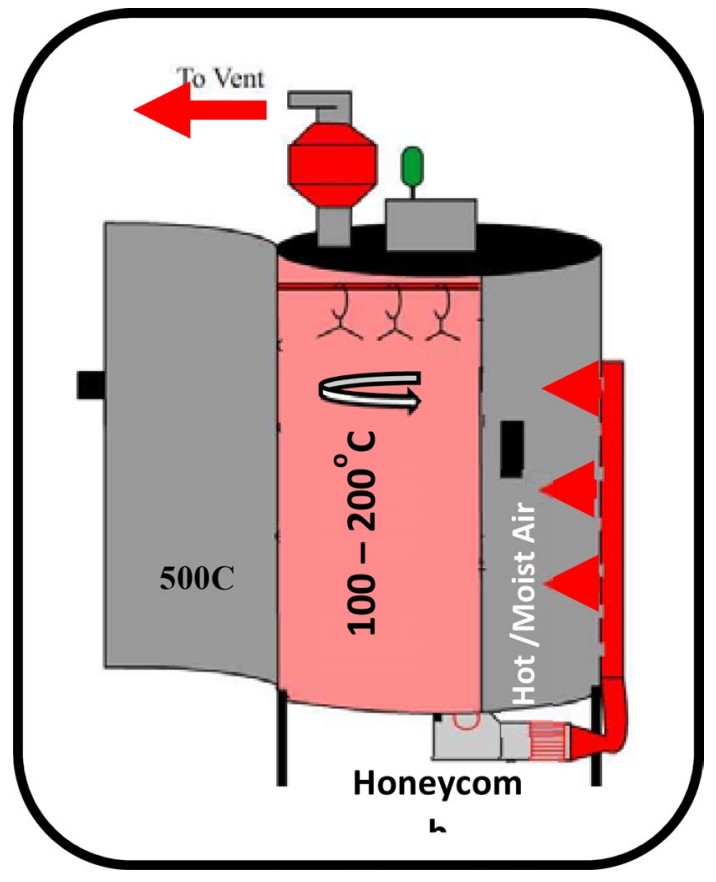

Fig. 3 Schematic of the honeycomb-based heat disinfecting unit

for cleaning surfaces and fogging applications in a hospital environment. However, sodium hypochlorite has some drawbacks including its inactivation in organic matter, corrosive nature to several metals and residue being left on surfaces. It is also not accepted for fogging on human beings since it causes mild to severe irritation to the skin, throat and eyes (Peck et al. 2011). Therefore, it requires PPE even to the person carrying out the fumigation. Hypochlorous acid $(\mathrm{HOCl})$ is the most effective chemical against pathogens, while it is $100 \%$ safe because it is chemical free, non-toxic and natural (Rahman et al. 2016). Applications of aqueous solutions containing approximately $30-2500 \mathrm{ppm} \mathrm{HOCl}$ extend to a variety of areas including wound care, dental care and as antimicrobial as well as virucidal agent (Park 2007). HOCl is also used widely for water treatment, food sanitization, hard surface disinfection, oil drilling and in cosmetics. It has been known to be used in the medical field for over a century even before antibiotics were available. $\mathrm{HOCl}$ targets bacteria or virus by chemically linking chlorine atoms to nucleotide bases that disrupt the function of bacterial DNA, impede metabolic pathways in which cells use enzymes to oxidize nutrients and release energy and other membrane-associated activities. HOCL can be synthesized through electrolysis of a brine solution by using mixed metal oxide (ruthenium oxide and iridium oxide)coated titanium electrodes and by applying currents in the range of 6-10 A. During the electrolysis process, the brine solution $(\sim 3.5 \% \mathrm{NaCl}$ in water) provides the chloride ion $\left(\mathrm{Cl}^{-}\right)$that is reduced to form chlorine gas. Chlorine gas produced chemically reacts with water to produce $\mathrm{HOCl}$, hydrogen ion $\left(\mathrm{H}^{+}\right)$and chloride ion $\left(\mathrm{Cl}^{-}\right)$following the reaction below (Hricova and Stephan 1934).

Chemical reactions at the anode:

$$
\begin{aligned}
& 2 \mathrm{H}_{2} \mathrm{O} \rightarrow 4 \mathrm{H}^{+}+\mathrm{O}_{2}+4 \mathrm{e}^{-}, \\
& 2 \mathrm{NaCl} \rightarrow \mathrm{Cl}_{2}+\mathrm{e}^{-}+2 \mathrm{Na}^{+}, \\
& \mathrm{Cl}_{2}+\mathrm{H}_{2} \mathrm{O} \rightarrow \mathrm{HOCl}+\mathrm{H}^{+}+\mathrm{Cl}^{-} .
\end{aligned}
$$

Chemical reactions at the cathode:
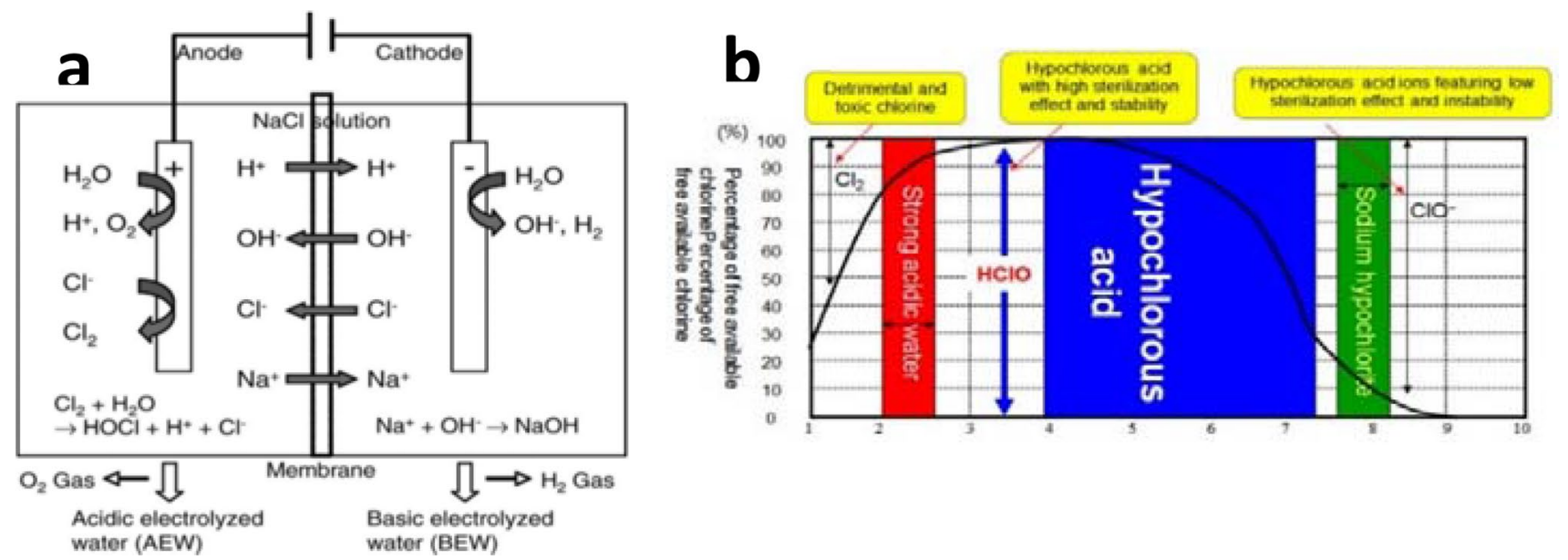

Fig. 4 a Electrolysis cell (reproduced from Hricova et al. 2008) and b comparisons for hypochlorous acid with different $\mathrm{pH}$ values (reproduced from https://www.superaquaholding.com/index.php/en/product-introduction-en/sterilization-en.html) 

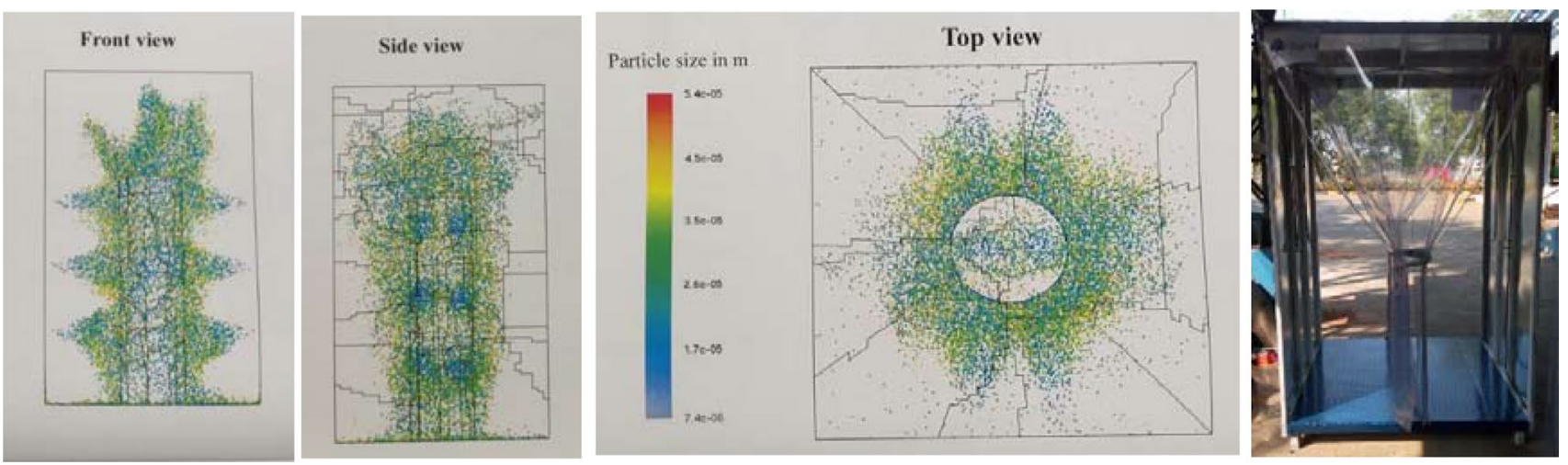

Fig. 5 Simulation study for disinfectant to be sprayed completely on the human body and picture of sensitization chambers

$2 \mathrm{H}_{2} \mathrm{O}+2 \mathrm{e}^{-} \rightarrow 2 \mathrm{OH}^{-}+\mathrm{H}_{2} \uparrow$

$2 \mathrm{Na}^{+}+2 \mathrm{OH}^{-} \rightarrow 2 \mathrm{NaOH}$.

Hypochlorous acid is most effective for disinfection between $\mathrm{pH} 4.5$ and 7 (Fig. 4).

ARCI embarked on designing a product 'Sanitising Chambers' for disinfecting the medical personnel wearing PPE kits and humans in partnership with Defence Research and Development Laboratory (DRDL), Hyderabad, and ESIC Medical College and Hospital, Hyderabad, with M/s Saffrongrid, Hyderabad, as partner for product development, fabrication and assembly. The sanitization chambers are installed and demonstrated at ESIC Medical College and Hospital, Hyderabad, to study its efficacy in sanitization of PPEs and humans. The sanitization system consists of three chambers of $1.5 \mathrm{~m} \times 1.5 \mathrm{~m} \times 2 \mathrm{~m}$ each wherein water is sprayed in first chamber, $\mathrm{HOCl}$ of 50-100 ppm concentration shall be sprayed in the second chamber and hot air is blown into the final chamber. The complete design of the chamber including size, material of construction and $\mathrm{HOCl}$ concentration are given by ARCI. Simulation studies for the optimization of pressure, nozzle size and number of nozzles are carried by DRDL (Fig. 4). Computational fluid dynamics (CFD) simulations are performed to predict mutliphase flow dynamics using well-proven CFD software for various type and number of injectors (with diameter $=0.2 \mathrm{~mm}$ with 0.06 lit per minute mass flow) and their positions on the top and side walls to arrive at an optimal solution so that the whole human body ( $450 \mathrm{~mm}$ diameter and $1700 \mathrm{~mm}$ height) is covered with sanitizer in an optimal time. Particle sizes of around $10 \mu \mathrm{m}$ with almost negligible velocity are observed near the human body. Fourteen injectors ( 6 on either side walls and 2 on top wall) are required to fully cover the human body with sanitizer particles of $10 \mu \mathrm{m}$ within about $15 \mathrm{~s}$. Testing of sanitization chambers and efficacy of $\mathrm{HOCl}$ as a disinfectant was carried out by ESIC Medical College and Hospital, Hyderabad. The results indicated that $100 \mathrm{ppm}$ $\mathrm{HOCl}$ is able to completely remove bacteria including E. Coli. The most interesting results are the studies performed on SARS-CoV-2, where complete disruption of virus was observed within $30 \mathrm{~s}$.

The fogging chamber is deployed at ESIC, Hyderabad, for the demonstration of the efficacy to eradicate bacterial growth (Fig. 5). For environmental decontamination applications, hypochlorous acid is not flammable and not known to release harsh chemicals and therefore is safe to be used. However, hypochlorous acid should not be mixed with ammonia-based products, as chloramines can be released.

\section{Summary}

ARCI has successfully developed three types of disinfection systems involving physical, thermal and chemical processes for disinfecting places and surfaces effectively, at medical as well as public settings to fight against COVID-19. The developed systems using UVC lamps, honeycomb-based air heater and $\mathrm{HOCl}$ fogging system are being tested in different hospital environments.

Acknowledgements The authors would like to acknowledge Dr. Samrat Sabat from University of Hyderabad, Mr. Mayank Agarwal from MEKINS Industries Ltd., Hyderabad, Mr. V. V. S. Rao, M/s. Sowbal Aerothermics, Dr. Jayathirth Joshi and Dr. Krishna Murthy from DRDL, Hyderabad, Dr. M. Srinivas, Dean, Dr. Gopinath, Dr. Aruna, Dr. Kiran, Dr. Madhuri and Dr. Ranjeet, ESIC Medical College and Hospital, Hyderabad, for their contributions.

\section{References}

(2008) Guideline for disinfection and sterilization in healthcare facilities. https://www.cdc.gov/infectioncontrol/guidelines/disinfecti on/index.html 
(2020) Heating the best method for disinfection of N95 masks, finds study. https://medicaldialogues.in/medicine/news/heating-bestmethod-for-disinfecting-n95-masks-finds-study-65499

Abreu AC, Tavares RR, Borges A, Mergulha F, Simoes M (2013) Current and emergent strategies for disinfection of hospital environments. J Antimicrob Chemother 68:2718-2732

Darnella MER, Subbarao K, Feinstonea SM, Taylor DR (2004) Inactivation of the coronavirus that induces severe acute respiratory syndrome, SARS-CoV. J Virol Methods 121:85-91

Djimeli L, Arfao AT, Ewoti OVN, Ebiane M (2014) Mixture of sodium hypochlorite and hydrogen peroxide on adhered Aeromonas hydrophila to solid substrate in water: impact of concentration and assessment of the synergistic effect. Int J Bacteriol. https:// doi.org/10.1155/2014/121367

Hofmann H, Pohlmann S (2004) Cellular entry of the SARS coronavirus. Trends Microbiol 12:466

Hricova D, Stephan R, Zweifel C (2008) Electrolyzed water and its application in the food industry. J Food Prot 71(9):1934

https://dst.gov.in/uv-disinfection-trolley-can-effectively-clean-hospi tal-spaces-combat-covid-19

https://www.alfaauv.com/blog/uv-and-disinfection-of-water/

https://www.epa.gov/pesticide-registration/selected-epa-registered -disinfectants.

https://www.superaquaholding.com/index.php/en/product-introducti on-en/sterilization-en.html

Johnson R, Saha BP, Rao VVS, Padmanabham G (2020) A device for disinfecting PPEs and the method there of. Patent Filed-E1/22078/2020/DEL

Kampf G, Todt D, Pfaender S, Steinmann E (2020) Persistence of coronaviruses on inanimate surfaces and their inactivation with biocidal agents. J Hosp Infect 104:246

Kwok YL, Gralton J, McLaws ML (2015) Face touching: a frequent habit that has implications for hand hygiene. Am J Infect Contr 43:112e 4
Lei Liao L et al (2020) Can N95 respirators be reused after disinfection? How many times? ACS Nano. https://doi.org/10.1021/acsna no.0c03597

Mackenzie D (2020) Reuse of N95 masks. Engineering (Article in press)

Malayeri AH et al (2020) Fluence (UV dose) required to achieve incremental log inactivation of bacteria, protozoa, viruses and algae (IUVA). IUVA News 18(3):4-6

McDevitt JJ, Rudnick SN, Radonovich LJ (2012) Aerosol susceptibility of influenza virus to UV-C light. Appl Environ Microbiol 78(6):1666-1669

Park GW et al (2007) Evaluation of liquid- and fog-based application of sterilox hypochlorous acid solution for surface inactivation of human norovirus. Appl Environ Microbiol 73:4463-4468

Peck B, Workeneh B, Kadikoy H, Patel SJ, Abdellati A (2011) Spectrum of sodium hypochlorite toxicity in man-also a concern for nephrologists. NDT Plus 4:231

Rahman SME, Imran Khan I, Oh DH (2016) Electrolyzed water as a novel sanitizer in the food industry: current trends and future perspectives. Compr Rev Food Sci Food Saf 15:471

Rutala WA, Weber DJ (2019) Best practices for disinfection of noncritical environmental surfaces and equipment in health care facilities: a bundle approach. Am J Infect Control 47:A96

Tseng CC, Li CS (2007) Inactivation of viruses on surfaces by ultraviolet germicidal irradiation. J Occup Environ Hyg 4:400-405

Van Doremalen N et al (2020) Aerosol and surface stability of SARSCoV-2 as compared with SARS-CoV-1. N Engl J Med 382:16

Zhou P, Yang XL, Shi ZL (2020) A pneumonia outbreak associated with a new coronavirus of probable bat origin. Nature 579:270

Publisher's Note Springer Nature remains neutral with regard to jurisdictional claims in published maps and institutional affiliations. 